\title{
Effect of colony morphology variation of Burkholderia pseudomallei on intracellular survival and resistance to antimicrobial environments in human macrophages in vitro
}

Sarunporn Tandhavanant ${ }^{1,2,3}$, Aunchalee Thanwisai ${ }^{1,2}$, Direk Limmathurotsakul ${ }^{2,4}$, Sunee Korbsrisate ${ }^{3}$, Nicholas PJ Day ${ }^{2,5}$, Sharon J Peacock ${ }^{1,2,6}$, Narisara Chantratita ${ }^{1,2^{*}}$

\begin{abstract}
Background: Primary diagnostic cultures from patients with melioidosis demonstrate variation in colony morphology of the causative organism, Burkholderia pseudomallei. Variable morphology is associated with changes in the expression of a range of putative virulence factors. This study investigated the effect of $B$. pseudomallei colony variation on survival in the human macrophage cell line U937 and under laboratory conditions simulating conditions within the macrophage milieu. Isogenic colony morphology types II and III were generated from 5 parental type I B. pseudomallei isolates using nutritional limitation. Survival of types II and III were compared with type I for all assays.
\end{abstract}

Results: Morphotype was associated with survival in the presence of $\mathrm{H}_{2} \mathrm{O}_{2}$ and antimicrobial peptide LL-37, but not with susceptibility to acid, acidified sodium nitrite, or resistance to lysozyme, lactoferrin, human neutrophil peptide-1 or human beta defensin-2. Incubation under anaerobic conditions was a strong driver for switching of type III to an alternative morphotype. Differences were noted in the survival and replication of the three types following uptake by human macrophages, but marked strain-to strain-variability was observed. Uptake of type III alone was associated with colony morphology switching.

Conclusions: Morphotype is associated with phenotypes that alter the ability of B. pseudomallei to survive in adverse environmental conditions.

\section{Background}

Burkholderia pseudomallei is an environmental Gramnegative bacterium that causes a severe and often fatal disease called melioidosis. This is an important cause of sepsis in south-east Asia and northern Australia, a geographic distribution that mirrors the presence of B. pseudomallei in the environment [1]. Melioidosis may develop following bacterial inoculation or inhalation and occurs most often in people with regular contact with contaminated soil and water [1]. Clinical manifestations of melioidosis are highly variable and range from fulminant septicemia to mild localized infection. The overall

\footnotetext{
* Correspondence: narisara@tropmedres.ac

'Department of Microbiology and Immunology, Faculty of Tropical Medicine, Mahidol University, Bangkok, Thailand

Full list of author information is available at the end of the article
}

mortality rate is $40 \%$ in northeast Thailand (rising to $90 \%$ in patients with severe sepsis) and $20 \%$ in northern Australia [1,2].

A major feature of melioidosis is that bacterial eradication is difficult to achieve. Fever clearance time is often prolonged (median 8 days), antimicrobial therapy is required for 12-20 weeks, and relapse occurs in around $10 \%$ of patients despite an appropriate course of antimicrobial therapy $[3,4]$. The basis for persistence in the infected human host is unknown, although several observations made to date may be relevant to the clinical behaviour of this organism [2,5]. B. pseudomallei can resist the action of bactericidal substances including complement and antimicrobial peptides in human serum [6-8]. B. pseudomallei can also survive after uptake by a range of phagocytic and non-phagocytic cells. Macrophages have several 
strategies to control bacterial infection, including bacterial killing following uptake through the action of reactive oxygen and reactive nitrogen compounds, antimicrobial peptides and lysozomal enzymes. Despite this, B. pseudomallei can invade and replicate in primary human macrophages [8-10].

Bacterial survival under adverse and rapidly changing environmental conditions is likely to be facilitated by phenotypic adaptability and plasticity. A previous study conducted by us found that $8 \%$ of primary cultures of clinical samples taken from patients with melioidosis contained more than one colony morphotype on Ashdown agar. Morphotypes could switch reversibly from one to another under specific conditions, and were associated with variable expression of putative virulence determinants including biofilm and flagella [11]. Compared with parental type I (the common 'cornflower head' morphology), isogenic type II (a small, rough colony) had increased biofilm and protease production, while isogenic type III (a large, smooth colony) was associated with increased flagella expression [11]. In vitro models suggested that switching of morphotype impacted on intracellular replication fitness after uptake by human epithelial cell line A549 and mouse macrophage cell line J774A.1. We postulated that colony morphology switching might represent a mechanism by which $B$. pseudomallei can adapt within the macrophage and persist in vivo.

In this study, we investigated whether the variable phenotype associated with different morphotypes resulted in altered fitness during interactions with the human macrophage cell line U937 and after exposure to a range of laboratory conditions that simulate one or more conditions within the macrophage milieu. Isogenic morphotypes II and III generated from each parental type I of 5 B. pseudomallei strains isolated from patients or soil were used in all experiments.

\section{Results}

\section{Growth curve analysis of isogenic morphotypes}

Different growth rates may affect the number of intracellular bacteria following uptake by host cells. Thus, prior to observation of intracellular replication in macrophages, extracellular growth of B. pseudomallei was compared between 3 isogenic morphotypes cultured in trypticase soy broth (TSB). Using a starting inoculum of $1 \times 10^{4} \mathrm{CFU} /$ $\mathrm{ml}, \log$ and stationary phase occurred at $2 \mathrm{~h}$ and $12 \mathrm{~h}$, respectively, for all 3 morphotypes. There was no difference in doubling time between 3 isogenic morphotypes $(P=0.14)$ with an average doubling time of 40.2, 39.2 and 38.3 minutes for types I, II and III, respectively.

\section{Replication of isogenic B. pseudomallei morphotypes in macrophages}

Evaluation of the initial B. pseudomallei-macrophage cell interaction using a multiplicity of infection (MOI) of
$25: 1$ demonstrated that $3.0 \%$ of the bacterial inoculum (range 1.2-8.0\% for different isolates) was associated with macrophages at $2 \mathrm{~h}$. There was no significant difference in this value between 3 isogenic morphotypes for all 5 isolates.

Following removal of extracellular bacteria and incubation for a further $2 \mathrm{~h}, 1.5 \%$ of the bacterial inoculum (range $0.4-3.4 \%$ for different isolates) was recovered. There was no significant difference in this value between 3 isogenic morphotypes for all 5 isolates.

The intracellular replication of B. pseudomallei between 4 to $8 \mathrm{~h}$ within macrophages is summarized in Figure 1. The replication rates for the 3 isogenic morphotypes of each strain obtained from two independent experiments were comparable (data not shown). Percent replication at $8 \mathrm{~h}$ was defined in relation to the $4 \mathrm{~h}$ time point, which was used as the reference count. Analysis of pooled data for 5 isolates demonstrated that type I had a significantly higher rate of intracellular replication than either type II or III. The mean intracellular replication of type I at $8 \mathrm{~h}$ was $2.0(95 \% \mathrm{CI} 1.5-2.6, P=0.004)$ times higher than that of type II, and 1.9 (95\%CI 1.4$2.5, P=0.004$ ) times higher than that of type III (Figure 1A). However, this pattern was not uniformly observed for each of the 5 isolates, as shown in Figure 1B-F. The higher replication fitness for type I based on the summary data was largely accounted for strains 164 and K96243. Other strains demonstrated a different pattern. For example, strain 153 type III had a higher intracellular replication than type I, a finding that replicates those of a previous study [11]. The mean intracellular bacterial count also varied between individual isolates. These differences were not due to the relative sensitivities of 3 isogenic morphotypes to $250 \mu \mathrm{g} / \mathrm{ml}$ kanamycin, as this experimental condition removed $99.9 \%$ of extracellular bacteria independent of type for all isolates (data not shown).

\section{Susceptibility of isogenic morphotypes to acid}

To examine the effect of acid, growth of 3 isogenic morphotypes in LB at pH 4.0, 4.5, 5.0 and 7.0 was compared at each of 5 time points over $24 \mathrm{~h}$ of incubation. No growth difference was observed between morphotypes at any time point for $\mathrm{pH} 4.5,5.0$ or $7.0(P>0.10$ for all time points). When cultured in LB broth at $\mathrm{pH} 4.0$, all bacteria died within $12 \mathrm{~h}$ incubation.

\section{Susceptibility of isogenic morphotypes to reactive oxygen intermediates (ROI)}

The susceptibility of 3 morphotypes to ROI was initially examined on LB agar plates containing a range of $\mathrm{H}_{2} \mathrm{O}_{2}$ concentrations $(0,170,310,625,1,250$ and 2,500 $\mu \mathrm{M})$ (data not shown). B. pseudomallei failed to grow on plates with $\mathrm{H}_{2} \mathrm{O}_{2}$ at a concentration higher than 


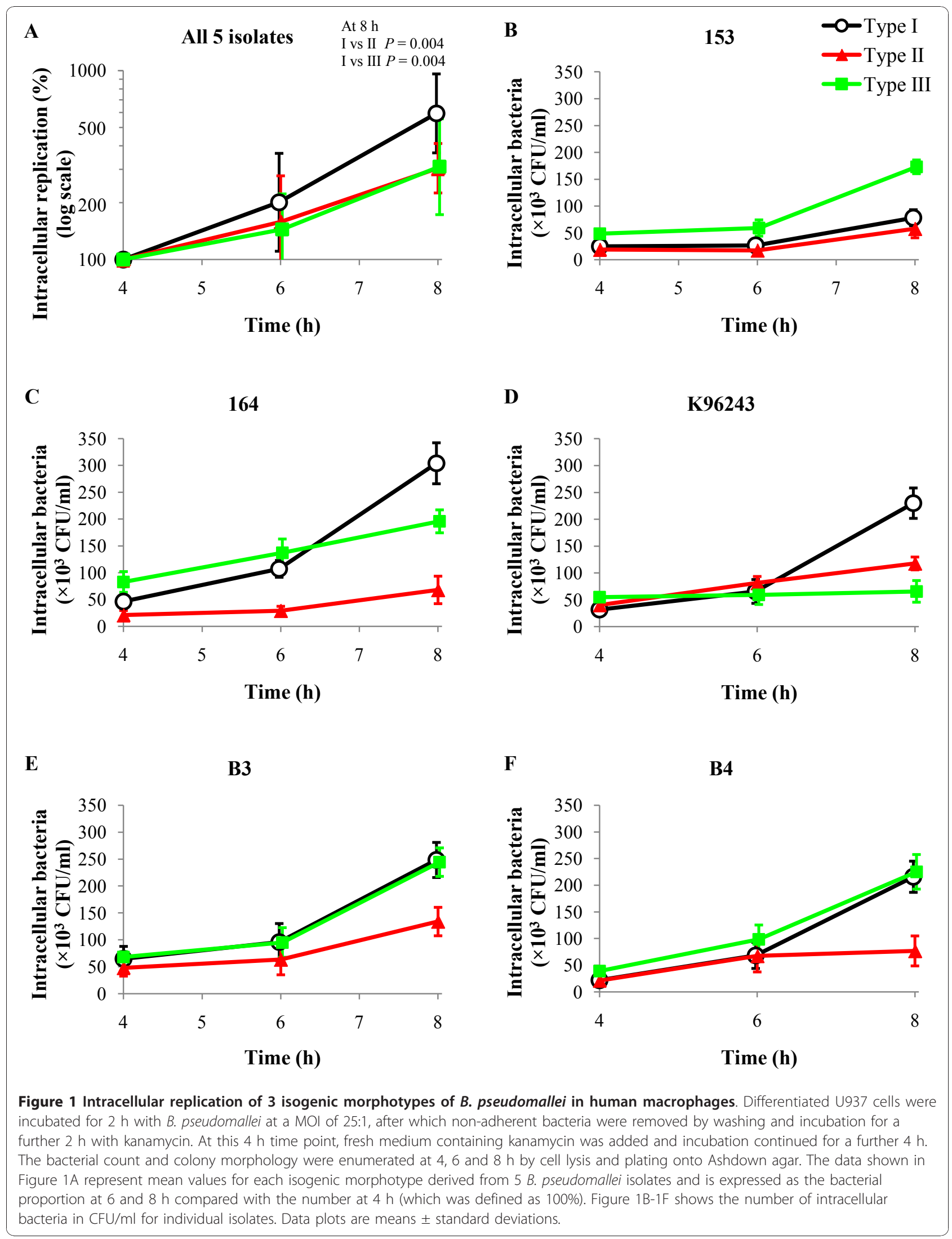


$625 \mu \mathrm{M}$, and so the percentage of viable bacteria were enumerated using agar plates with $625 \mu \mathrm{M} \mathrm{H} \mathrm{H}_{2} \mathrm{O}_{2}$ compared to those on plates without $\mathrm{H}_{2} \mathrm{O}_{2}$. This demonstrated a difference in bacterial survival between the three isogenic morphotypes $(P<0.001)$. Percentage survival of type I was 3.8 (95\% CI 2.9-5.0, $P<0.001$ ) times higher than that for type II, and was 5.2 (95\% CI 4.0-6.8, $P<0.001)$ times higher than that for type III (Figure 2A).

Further examination was undertaken of the susceptibility of the 3 morphotypes with a range of concentrations of $\mathrm{H}_{2} \mathrm{O}_{2}$ in LB broth. No bacteria survived in $500 \mu \mathrm{M}$ and $250 \mu \mathrm{M} \mathrm{H}_{2} \mathrm{O}_{2}$. In $125 \mu \mathrm{M} \mathrm{H}_{2} \mathrm{O}_{2}$, type I of all 5 isolates multiplied from $1 \times 10^{6} \mathrm{CFU} / \mathrm{ml}$ (the starting inoculum) to between $5 \times 10^{7}$ and $2.1 \times 10^{8} \mathrm{CFU} / \mathrm{ml}$. By contrast, all 5 type III and 4 type II isolates (the exception being type II derived from isolate 164) obtained from the same experiment demonstrated no growth on the plates.
This confirmed a higher resistance to $\mathrm{H}_{2} \mathrm{O}_{2}$ of parental type I compared to types II and III. A difference was also observed between three isogenic morphotypes in $62.5 \mu \mathrm{M} \mathrm{H}_{2} \mathrm{O}_{2}(P<0.001)$. Bacterial growth of type I was 1.5 (95\% CI 1.1-2.0, $P=0.02$ ) times higher than that for type II, and was $2.7(95 \%$ CI $2.0-3.7, P<0.001)$ times higher than that for type III.

\section{Susceptibility of isogenic morphotypes to reactive nitrogen intermediates (RNI)}

Susceptibility of B. pseudomallei to RNI was observed following $6 \mathrm{~h}$ exposure to various concentrations of $\mathrm{NaNO}_{2}$ ranging between 0.1 to $10 \mathrm{mM}$ in acidified $\mathrm{pH}$ 5.0 in LB broth. Using a concentration of $2 \mathrm{mM}$ $\mathrm{NaNO}_{2}$, the percent survival of types I, II and III were $43.8 \%, 43.7 \%$ and $40.1 \%$, respectively, with no difference observed between the three morphotypes $(P>0.10)$.

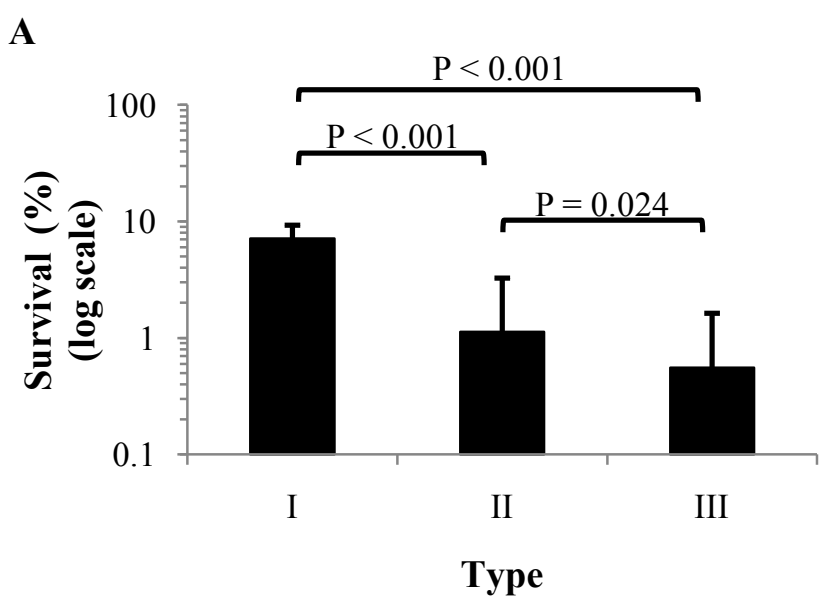

B

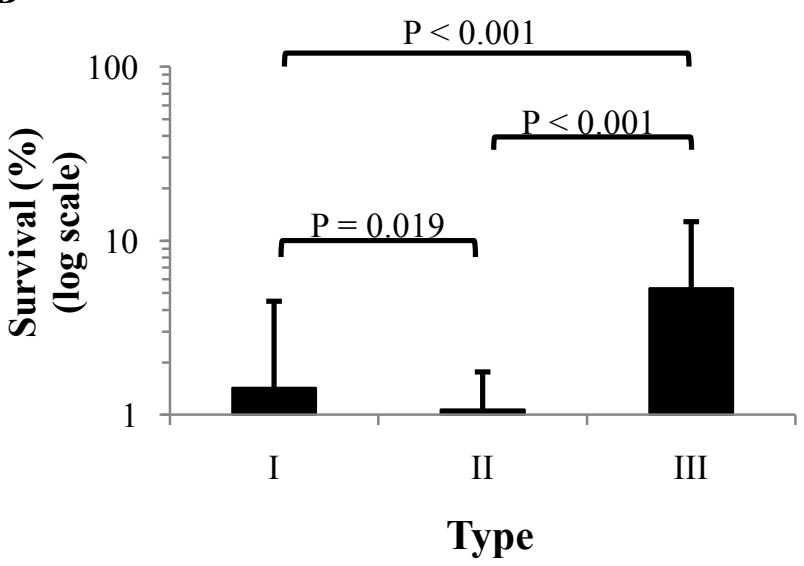

Figure 2 Susceptibility of 3 isogenic morphotypes of $B$. pseudomallei to ROI and antimicrobial peptide LL-37. Survival was examined for 5 different $B$. pseudomallei isolates. (A) Percent survival in $\mathrm{ROI}$ was determined on LB agar plates containing $625 \mu \mathrm{M} \mathrm{H} \mathrm{H}_{2}$ compared to the number of bacteria on plates without $\mathrm{H}_{2} \mathrm{O}_{2}$. The results were obtained from 4 separate experiments. (B) Percent survival in $\mathrm{LL}-37$ was determined at $6.25 \mu \mathrm{M} \mathrm{LL}-37$ in $1 \mathrm{mM}$ potassium phosphate buffer (PPB) pH 7.4 for $6 \mathrm{~h}$. The results were obtained from 2 separated experiments. Data plots are means \pm standard deviations. 


\section{Susceptibility of isogenic morphotypes to lysozyme and lactoferrin}

Compared with initial inocula and untreated controls, treatment with $200 \mu \mathrm{g} / \mathrm{ml}$ lysozyme at pH 5.0 did not decrease the bacterial count for the 3 isogenic morphotypes of B. pseudomallei, while this concentration could reduce the number of $E$. coli from $4.9 \times 10^{6} \mathrm{CFU} / \mathrm{ml}$ (the starting inoculum) to $425 \mathrm{CFU} / \mathrm{ml}$. Susceptibility was examined further in the presence of $3 \mathrm{mg} / \mathrm{ml}$ lactoferrin. A kinetic study over time demonstrated that lactoferrin alone could kill an entire $E$. coli inoculum of $1 \times 10^{6} \mathrm{CFU} / \mathrm{ml}$ within $3 \mathrm{~h}$ at $\mathrm{pH} 5.0$. The same treatment did not affect the number of viable $B$. pseudomallei which was comparable to the inoculum and untreated control. Adding $200 \mu \mathrm{g} / \mathrm{ml}$ lysozyme with lactoferrin did not enhance the killing efficacy of $E$. coli and had no effect on B. pseudomallei.

\section{Susceptibility of isogenic morphotypes to antimicrobial peptides}

Macrophages produce several antimicrobial peptides $[12,13]$. We examined the susceptibility of isogenic morphotypes to HNP-1, HBD-2 and cathelicidin LL-37, three of the main human antimicrobial peptides. The results demonstrated that $100 \mu \mathrm{g} / \mathrm{ml} \mathrm{HNP-1}$ and $100 \mu \mathrm{g} / \mathrm{ml} \mathrm{HBD}-2$ did not reduce the bacterial count for the 3 isogenic morphotypes of any of the B. pseudomallei isolates when compared with the initial inocula and untreated controls.

In a pilot experiment with a range of LL-37 concentrations and exposure times, we found that LL-37 reduced the $B$. pseudomallei count at a concentration of $6.25 \mu \mathrm{M}$ at $6 \mathrm{~h}$. This condition killed $100 \%$ of a starting inoculum of $4.6 \times 10^{6} \mathrm{CFU} / \mathrm{ml} \mathrm{E}$. coli control and caused a 75.7 to $99.8 \%$ reduction of $B$. pseudomallei for different isolates. A difference in bacterial survival was observed between the three isogenic morphotypes $(P<$ $0.001)$. Survival of type I was 1.5 (95\%CI 1.1-2.2, $P=$ 0.02 ) times higher than that for type II, but was 3.7 (95\%CI 2.6-5.3, $P<0.001$ ) times lower than that for type III (Figure 2B).

\section{Growth in low oxygen concentrations}

Low oxygen concentration may limit the intracellular growth of aerobic bacteria within the host [14]. We examined the survival of 3 isogenic morphotypes and determined whether morphotype switching occurred in response to different oxygen concentrations during incubation on Ashdown agar at $37^{\circ} \mathrm{C}$. B. pseudomallei survived in 5-15\% oxygen concentration for 14 days, with an average colony count of 95\% (range 72-109\% for different isolates and morphotypes) compared to control plates incubated in air for 4 days (Table 1 ). There was no difference in the survival pattern between 3 isogenic morphotypes $(P>0.10)$. B. pseudomallei colonies were not visible on Ashdown agar after incubation in an anaerobic chamber for 2 weeks. The capability to recover from anaerobic conditions was observed as colonies were visible at $48 \mathrm{~h}$ after reincubation at $37^{\circ} \mathrm{C}$ in air, and colony counts were performed after incubation for 4 days. The percentage of bacteria recovered was not different between three morphotypes $(P>0.10)$.

\section{Effect of laboratory conditions on morphotype switching}

Types I and II did not demonstrate colony morphology variation over time in any of the conditions tested. Figure 3 shows the effect of various testing conditions of type III for all 5 isolates. Between $1 \%$ and $13 \%$ of colonies subcultured from $28 \mathrm{~h}$ TSB culture onto Ashdown agar switched to alternative types. The switching of type III appeared to be important for replication in macrophages. Following uptake, switching of type III increased over time such that by the $8 \mathrm{~h}$ time point, between 48 99\% of the agar plate colonies (the range representing differences between isolates) had switched to type I (isolates K96243, 164, B3 and B4) or to type II (isolate 153). Morphotype switching did not increase in acid, acidified sodium nitrite, or LL-37. In contrast, morphotype switching from broth culture containing $62.5 \mu \mathrm{M} \mathrm{H}_{2} \mathrm{O}_{2}$ increased over time of incubation, ranging between $24-49 \%$ of the plate colonies for different isolates. Interestingly, between $15-100 \%$ of the total type III colony count switched to an alternative morphotype after recovery from anaerobic conditions. The pattern of morphotype switching in all conditions tested was specific to isolates, with four isolates switching from type III to type I (K96243, 164, B3 and B4), and one isolate switching to II (153).

\section{Discussion}

Our previous paper reported a process of B. pseudomallei colony morphology switching that occurred during human melioidosis, and in an animal model, mouse macrophage cell line J774A.1, human lung epithelial cell line A549, and under starvation conditions in vitro. In this study, we investigated whether the variable phenotype associated with different morphotypes resulted in a survival fitness or disadvantage during interactions with a human macrophage cell line U937 and after exposure to factors that simulate the macrophage milieu. Although our previous report described 7 different morphotypes from clinical isolates, the five isolates used here from 3 different clinical and 2 environmental samples were only observed to switch under nutritional limitation from parental type I to types II and III, allowing comparison of 3 isogenic morphotypes with known variable phenotype. 
Table 1 Growth and morphotype switching of 3 isogenic morphotypes derived from 5 B. pseudomallei isolates following incubation in low oxygen and anaerobic conditions

\begin{tabular}{|c|c|c|c|c|c|c|c|c|c|}
\hline \multirow{4}{*}{$\begin{array}{l}\text { Starting } \\
\text { type } \\
\text { I (parental) }\end{array}$} & \multicolumn{9}{|c|}{ Atmospheric conditions during incubation at $37^{\circ} \mathrm{C}$} \\
\hline & \multicolumn{3}{|c|}{ Air for 4 days (control) } & \multicolumn{3}{|c|}{$5-15 \%$ oxygen for 14 days } & \multicolumn{3}{|c|}{$\begin{array}{l}\text { Reincubated in air for } 4 \text { days following } \\
\text { anaerobic conditions for } 14 \text { days }\end{array}$} \\
\hline & \multirow{2}{*}{$\begin{array}{c}\text { Mean colony } \\
\text { count, } \\
\text { (range) }\end{array}$} & \multicolumn{2}{|c|}{$\begin{array}{l}\text { *Morphotype, } \\
\% \text { (range) }\end{array}$} & \multirow{2}{*}{$\begin{array}{c}\text { Mean \% colony count } \\
\text { compared with control in air } \\
\text { (range) } \\
\begin{array}{c}92 \% \\
(78-108 \%)\end{array}\end{array}$} & \multicolumn{2}{|c|}{$\begin{array}{l}\text { *Morphotype, } \\
\% \text { (range) }\end{array}$} & \multirow{2}{*}{$\begin{array}{l}\text { Mean \% colony count } \\
\text { compared to control in air } \\
\text { (range) } \\
86 \% \\
(57-138 \%)\end{array}$} & \multicolumn{2}{|c|}{$\begin{array}{l}\text { *Morphotype, } \\
\% \text { (range) }\end{array}$} \\
\hline & & I & $100 \%$ & & I & $100 \%$ & & I & $100 \%$ \\
\hline$\|$ & $\begin{array}{c}90 \\
(62-150)\end{array}$ & $\|$ & $100 \%$ & $\begin{array}{c}91 \% \\
(72-109 \%)\end{array}$ & $\|$ & $100 \%$ & $\begin{array}{c}95 \% \\
(66-127 \%)\end{array}$ & $\|$ & $100 \%$ \\
\hline \multirow[t]{2}{*}{ III } & $\begin{array}{c}123 \\
(110-141)\end{array}$ & III & $\begin{array}{c}89 \% \\
(81-98 \%)\end{array}$ & $\begin{array}{c}98 \% \\
(78-107 \%)\end{array}$ & III & $\begin{array}{c}89 \% \\
(81-99 \%)\end{array}$ & $\begin{array}{c}80 \% \\
(48-94 \%)\end{array}$ & III & $\begin{array}{c}17 \% \\
(0-85 \%)\end{array}$ \\
\hline & & $\begin{array}{l}\text { | or } \\
\text { || }\end{array}$ & $\begin{array}{c}11 \% \\
(2-19 \%)\end{array}$ & & | or || & $\begin{array}{c}11 \% \\
(1-19 \%)\end{array}$ & & I or & $\begin{array}{c}83 \% \\
(15-100 \%)\end{array}$ \\
\hline
\end{tabular}

The data represents the mean of 5 B. pseudomallei isolates for each morphotype. The range reflected variation of \% colony count between isolates. *\% Morphotype was the proportion of each morphotype on the plate. Morphotype switching was observed for type III (starting type) to either type I (isolates K96243, 164, B3 and B4) or to type II (isolate 153).

The initial interaction between the human macrophage cell line U937 and 3 isogenic morphotypes of B. pseudomallei was not different between the three types. Despite a comparable rate of extracellular growth between isogenic morphotypes, heterogeneity in subsequent intracellular survival/growth after this time point was observed. Type III of each isolate was inconsistently capable of multiplication after uptake by human macrophages, and was associated with a change in morphotype. This suggests that type III has a fitness disadvantage under these circumstances. A possible explanation for this is that type III does not appear to produce biofilm [11]. A biofilm mutant demonstrated a mark reduction in intracellular survival in primary human macrophages than the wild

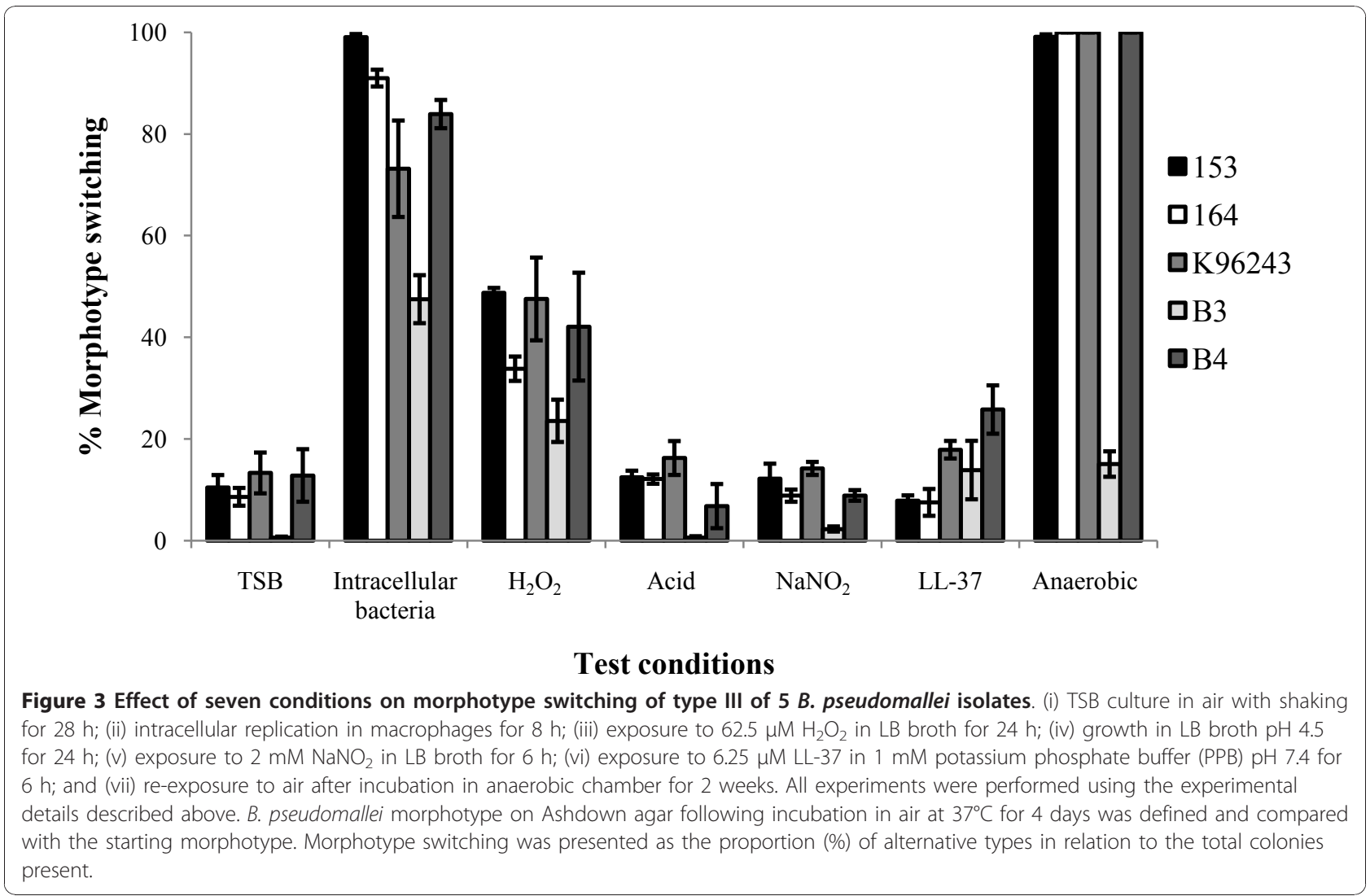


type, suggesting that biofilm production is associated with the ability to survive in human macrophages [8].

Our previous study examined the survival and replication of B. pseudomallei strain 153 in the human respiratory epithelial cell line A549 and the mouse macrophage cell line J744A.1. Our finding here that type III of strain 153 had increased survival in the human macrophage cell line U937 is consistent with our previous findings for the mouse macrophage cell line J774A.1 infected with the same strain [11]. However, the use of a wider number of strains in this study demonstrated that there was a lack of reproducibility between strains. We suggest that this is likely relate to variability in genomic content between the strains tested. Future testing strategies require the evaluation of a large numbers of strains that have undergone whole genome sequencing to facilitate statistically robust comparisons between genomic variation and phenotypic behaviour.

Several components of the innate immune system are efficient in killing organisms within human macrophages [15]. The most important of these are the antimicrobial peptides and nitric oxide (NO), the superoxide anion $\left(\mathrm{O}_{2}{ }^{-}\right)$, and hydrogen peroxide $\left(\mathrm{H}_{2} \mathrm{O}_{2}\right)$, all of which are directly toxic to bacteria. Reactive oxygen species generated by the phagocyte NADPH oxidase have an essential role in the control of $B$. pseudomallei infection in C57BL/6 bone marrow derived macrophages [16]. Type I of all $5 \mathrm{~B}$. pseudomallei isolates tested here had the greatest resistance to $\mathrm{H}_{2} \mathrm{O}_{2}$, followed by types II and III, respectively, suggesting that type I has the greatest potential to scavenge or degrade $\mathrm{H}_{2} \mathrm{O}_{2}$ molecules. This may explain the finding that type I had the highest replication after uptake by the macrophage cell line. Type III switched to type I or II during culture in medium containing $\mathrm{H}_{2} \mathrm{O}_{2}$, indicated that type III had a survival disadvantage under such conditions that required switching to a more $\mathrm{H}_{2} \mathrm{O}_{2}$ resistant type.

One of the mechanisms by which $B$. pseudomallei escapes macrophage killing is by repressing inducible nitric oxide synthase (iNOS) by activating the expression of two negative regulators, a suppressor of cytokine signaling 3(SOC3) and cytokione-inducible src homology2containing protein (CIS) [17]. It is unknown whether there are variation between strains and isogenic morphotypes in the ability to interfere with iNOS induction. However, colony morphology differences did not influence resistance to RNI. B. pseudomallei is protected from RNI by the production of alkyl hydroperoxide reductase $(\mathrm{AhpC})$ protein and depends on OxyR regulator and a compensatory KatG expression [18]. These mechanisms may not be associated with colony morphology variability.

B. pseudomallei survive in the phagolysosome [10] which are acidified environments containing lysozymes, proteins and antimicrobial peptides that destroy pathogen. There was no difference in growth for the 3 isogenic morphotypes of $B$. pseudomallei derived from all five isolates at all $\mathrm{pH}$ levels tested above 4.0, but a $\mathrm{pH}$ of 4.0 was universally bactericidal, suggesting that morphotype switching did not provide a survival advantage against acid conditions.

All morphotypes of $B$. pseudomallei were highly resistance to lysozyme and lactoferrin. Lysozyme functions to dissolve cell walls of bacteria. Lactoferrin is a competitor that works by binding iron and preventing uptake by the bacteria. Common structures for resistance to these factors such as capsule and LPS [8] were present in all isogenic morphotypes [11]. An alternative explanation is that $B$. pseudomallei may produce a morphotypeindependent lysozyme inhibitor that counteracts the action of lysozyme and lactoferrin.

Antimicrobial peptides are efficient at killing a broad range of organisms. They are distributed in variety tissues, and in neutrophils and macrophages [12,13]. All 3 isogenic $B$. pseudomallei morphotypes were resistant to $\alpha$-defensin HNP-1 and $\beta$-defensin HBD-2, but were susceptible to LL-37. In contrast to sensitivity to $\mathrm{H}_{2} \mathrm{O}_{2}$, type III was more resistant than type I or II to LL-37. This ability may allow type III to survive within host cells for a limited period before successfully switching to alternative phenotypes and may provide a fitness of advantage in macrophages.

Another feature of bacterial survival during the establishment of persistent infection in the host is adaptation to hypoxia in the host microenvironment [14]. This study demonstrated that all 3 isogenic morphotypes were able to tolerate a low oxygen concentration and anaerobic conditions for at least two weeks. Type III switching to either type I or II was observed during recovery from anaerobic incubation. The fact that types I and II were stable following anaerobic incubation suggests that they are tolerant of fluctuations in oxygen concentration.

Given the variation in the genome of different B. pseudomallei, it was not surprising to observe some variation in intracellular replication between isogenic morphotypes of different isolates. Only one strain switched from type III to II, while the other four isolates switched from type III to type I in all conditions in which a change in morphotype was observed. Analyses of 5 isolates in this study provide evidence that colony morphology variation represents heterogeneous phenotypes of $B$. pseudomallei with different fitness advantages to interact, survive and replicate in the presence of bactericidal substances within human macrophages.

A limitation of this study is that the experimental methods were laborious and time consuming, which restricted the number of strains we could examine. It is 
also unclear whether these in vitro assays using a human macrophage cell line are a good model for human infection. Further studies are required to determine the molecular mechanism of morphotype switching, and whether this is associated with persistence of B. pseudomallei in the human host.

\section{Conclusions}

B. pseudomallei can produce different colony morphologies in vivo and in vitro. This study has described the intracellular survival and replication of two isogenic morphotypes II and III generated from 5 different parental type I B. pseudomallei in the U937 human macrophage cell line, and has examined the survival of these isogenic morphotypes compared to the parental types in the presence of a variety of substances and under conditions which are potentially encountered within the macrophage milieu. Data for 5 isolates demonstrated that there was variability in bacterial survival and replication following uptake by human macrophages between parental type I and types II or III, as well as variability between strains. Uptake of type III alone was associated with colony morphology switching. Type I was associated with survival in the presence of $\mathrm{H}_{2} \mathrm{O}_{2}$. In contrast, isogenic morphotype III demonstrated higher resistance to antimicrobial peptide LL-37. Specific morphotypes were not associated with survival with susceptibility to acid, acidified sodium nitrite, or resistance to lysozyme, lactoferrin, HNP-1 or HBD-2. Incubation under anaerobic conditions was a strong driver for switching of type III to an alternative morphotype in all isolates.

\section{Methods}

Bacterial isolates and isolation of isogenic morphotypes

Five $B$. pseudomallei isolates were examined in this study. Isolates 153, 164 and the reference isolate K96243 were cultured from cases of human melioidosis in Thailand, and isolates B3 and B4 were cultured from uncultivated land in northeast Thailand [19]. The colony morphology of all five parental isolates was type I, and isogenic types II and III were generated from type I of each strain using nutritional limitation [11]. Briefly, a single colony of type I on Ashdown agar was inoculated into $3 \mathrm{ml}$ of TSB and incubated at $37^{\circ} \mathrm{C}$ in air in static conditions for 21 days. Bacterial culture was diluted and spread plated onto Ashdown agar. Morphotypes were identified using a morphotyping algorithm [11]. Isogenic types II and III generated from each parental type I were isolated from the plates of each strain.

\section{Growth curve analysis}

Growth curves were performed for the 3 isogenic morphotypes of each of the $5 \mathrm{~B}$. pseudomallei isolates.
A colony of B. pseudomallei was suspended in sterile phosphate buffered saline (PBS). The bacterial suspension was adjusted to an optical density (OD) at $600 \mathrm{~nm}$ of 0.15 and diluted 100 times. One hundred microlitres of bacterial suspension was added to $10 \mathrm{ml}$ of TSB and incubated at $37^{\circ} \mathrm{C}$ in air with shaking at $200 \mathrm{rpm}$ for 28 h. At $2 \mathrm{~h}$ intervals, $100 \mu \mathrm{l}$ of bacterial culture was removed, serially diluted 10 -fold in PBS, and the bacterial count determined by plating on Ashdown agar in duplicate and performing a colony count following incubation at $37^{\circ} \mathrm{C}$ in air for 4 days. Doubling time was calculated.

\section{Cell line and culture conditions}

Human monocyte-like cell line U937 (ATCC CRL1593.2) originating from a histiocytic lymphoma was maintained in RPMI 1640 (Invitrogen) supplemented with $10 \%$ heat-inactivated fetal bovine serum (PAA Laboratories), 100 units $/ \mathrm{ml}$ of penicillin and $100 \mu \mathrm{g} / \mathrm{ml}$ of streptomycin (Invitrogen) and cultured at $37^{\circ} \mathrm{C}$ in a $5 \% \mathrm{CO}_{2}$ humidified incubator [20]. Before exposure to B. pseudomallei, $1 \times 10^{5} \mathrm{U} 937$ cells per well were transferred to a 24 well-tissue culture plate (BD Falcon) and activated by the addition of $50 \mathrm{ng} / \mathrm{ml}$ of phorbol 12 myristate 13-acetate (PMA) (Sigma) over 2 days [20]. The medium was then replaced with $1 \mathrm{ml}$ of fresh medium without PMA and incubated for 1 day. The differentiated macrophage was assessed by macrophage-like morphology [21]. Following washing 3 times with $1 \mathrm{ml}$ of Hank's balance salt solution (HBSS) (Sigma), $1 \mathrm{ml}$ of fresh medium was gently added to the macrophages.

Interaction of $B$. pseudomallei isogenic morphotypes with human macrophages

The interaction assay was performed as previously described [11]. B. pseudomallei from an overnight culture on Ashdown agar was suspended in PBS, the bacterial concentration adjusted using OD at $600 \mathrm{~nm}$ and then diluted in PBS and inoculated into wells containing differentiated U937 cells to obtain an MOI of approximately 25 bacteria per cell. The MOI was verified by colony counting on Ashdown agar. Infected U937 cells were incubated at $37^{\circ} \mathrm{C}$ in $5 \% \mathrm{CO}_{2}$ for $2 \mathrm{~h}$. Non-adherent bacteria were removed by washing gently 3 times with $1 \mathrm{ml}$ of PBS. The U937 cells were lysed with $1 \mathrm{ml}$ of $0.1 \%$ Triton X-100 (Sigma), and the cell lysates serially diluted in PBS and spread plated on Ashdown agar to obtain the bacterial count. Colony morphology was observed [11]. The percentage of bacteria that were cell-associated was calculated by (number of associated bacteria $\times 100$ )/number of bacteria in the inoculum. The experiment was performed in duplicate for 2 independent experiments.

Intracellular survival and multiplication of B. pseudomallei in human macrophages were determined at a 
series of time points following the initial co-culture described above of differentiated U937 with B. pseudomallei for $2 \mathrm{~h}$. Following removal of extracellular bacteria and washing 3 times with PBS, medium containing $250 \mu \mathrm{g} / \mathrm{ml}$ kanamycin (Invitrogen) was added and incubated for a further $2 \mathrm{~h}$ ( $4 \mathrm{~h}$ time point). New medium containing $20 \mu \mathrm{g} / \mathrm{ml}$ kanamycin was then added to inhibit overgrowth by any remaining extracellular bacteria at further time points. Intracellular bacteria were determined at 4, 6 and $8 \mathrm{~h}$ after initial inoculation. Infected cells were washed, lysed and plated as above. Intracellular survival and multiplication of B. pseudomallei based on counts from cell lysates were presented. Percent intracellular bacteria was calculated by (number of intracellular bacteria at $4 \mathrm{~h}$ ) $\times 100 /$ number of bacteria in the inoculum. Percent intracellular replication was calculated by (number of intracellular bacteria at 6 or $8 \mathrm{~h} \times$ 100)/number of intracellular bacteria at $4 \mathrm{~h}$. The experiment was performed in duplicate for 2 independent experiments.

\section{Growth in acid conditions}

B. pseudomallei from an overnight culture on Ashdown agar was suspended in PBS and adjusted using OD at $600 \mathrm{~nm}$ to a concentration of $1 \times 10^{6} \mathrm{CFU} / \mathrm{ml}$ in PBS. Thirty microlitres of bacterial suspension was inoculated into $3 \mathrm{ml}$ of Luria-Bertani (LB) broth at a pH 4.0, 4.5 or 5.0. The broth was adjusted to acid $\mathrm{pH}$ with $\mathrm{HCl}$. Growth in LB broth at pH 7.0 was used as a control. The culture was incubated at $37^{\circ} \mathrm{C}$ in air with shaking at $200 \mathrm{rpm}$. At 1, 3, 6, 12 and $24 \mathrm{~h}$ time intervals, the culture was aliquoted and viability and growth determined by serial dilution and plating on Ashdown agar.

\section{Susceptibility of $B$. pseudomallei to reactive oxygen intermediates (ROI)}

The sensitivity of $B$. pseudomallei to reactive oxygen intermediates was determined by growth on oxidant agar plates and in broth containing $\mathrm{H}_{2} \mathrm{O}_{2}$. Assays on agar plates were performed as described previously [22], with some modifications. Briefly, an overnight culture of B. pseudomallei harvested from Ashdown agar was suspended in PBS and the bacterial concentration adjusted using OD at $600 \mathrm{~nm}$. A serial dilution of the inoculum was spread plated onto Ashdown agar to confirm the bacterial count and colony morphology. Ten microlitres of serial dilutions of bacteria in PBS were spotted onto LB agar containing $0,170,310,625,1,250$ and 2,500 $\mu \mathrm{M}$ $\mathrm{H}_{2} \mathrm{O}_{2}$. Colony counts were performed after incubation at $37^{\circ} \mathrm{C}$ in air for $24 \mathrm{~h}$. The number of colonies on plates containing $\mathrm{H}_{2} \mathrm{O}_{2}$ was compared with that on control plates and presented as bacterial survival (\%). The assay was performed for 4 independent experiments.
Sensitivity to killing by hydrogen peroxide was further examined in LB broth. An overnight culture of B. pseudomallei on Ashdown agar was suspended in PBS and adjusted to approximately $1 \times 10^{8} \mathrm{CFU} / \mathrm{ml}$. Ten microlitres of bacterial suspension was added into $1 \mathrm{ml}$ of LB broth containing two-fold decreasing concentrations of $\mathrm{H}_{2} \mathrm{O}_{2}$ ranging from 500 to $31.25 \mu \mathrm{M}$. The mixtures were statically incubated at $37^{\circ} \mathrm{C}$ in air for $24 \mathrm{~h}$ and then the viable count and colony morphotype were determined by serial dilution and plating on Ashdown agar. The experiment was performed for 2 independent experiments.

\section{Susceptibility of $B$. pseudomallei to reactive nitrogen intermediates (RNI)}

B. pseudomallei from an overnight culture on Ashdown agar was suspended in PBS and the bacterial concentration adjusted using OD at $600 \mathrm{~nm}$. Thirty microlitres of bacterial suspension was added into $3 \mathrm{ml}$ of two-fold decreasing concentrations of sodium nitrite (ranging from 10 to $0.1 \mathrm{mM}$ ) in $\mathrm{LB}$ broth at $\mathrm{pH}$ 5.0. The mixture was incubated at $37^{\circ} \mathrm{C}$ in air with shaking at $200 \mathrm{rpm}$ and viable bacteria were determined at $6 \mathrm{~h}$ by serial dilution and plating on Ashdown agar. The number of viable bacteria in the presence of $\mathrm{NaNO}_{2}$ was compared with the number of bacteria in the inoculum and presented as bacterial survival (\%). The experiment was performed in duplicate for 2 independent experiments.

\section{Susceptibility of $B$. pseudomallei to lysozyme and lactoferrin}

B. pseudomallei cultured overnight on Ashdown agar was harvested and suspended in $10 \mathrm{mM}$ Tris- $\mathrm{HCl}$ buffer $\mathrm{pH} 5.0$ [23]. The bacterial suspension was adjusted to a concentration of $1 \times 10^{7} \mathrm{CFU} / \mathrm{ml}$. Fifty microlitres of bacterial suspension was added to an equal volume of $400 \mu \mathrm{g} / \mathrm{ml}$ chicken egg white lysozyme $(48,000 \mathrm{U} / \mathrm{mg}$ protein) (Sigma) to obtain a final concentration of $200 \mu \mathrm{g} / \mathrm{ml}$. The mixture was incubated at $37^{\circ} \mathrm{C}$ in air for $24 \mathrm{~h}$, after which $10 \mu \mathrm{l}$ of 10 -fold serial dilutions were dropped on Ashdown agar. Sensitivity to lysozyme was also tested in the presence of $3 \mathrm{mg} / \mathrm{ml}$ lactoferrin (Sigma) in a separate experiment [23]. E. coli strain HB101 was tested in parallel as a control.

\section{Susceptibility to human $\alpha$-defensin and $\beta$-defensin}

B. pseudomallei was tested for resistance to HNP-1 and HBD-2 (Peptide international) as described previously [24], with the exception that HNP-1 was used at twice the dose. E. coli strain HB101 was tested in parallel as a control. Briefly, B. pseudomallei or E. coli strain HB101 colonies were washed and suspended in $1 \mathrm{mM}$ sodium phosphate buffer pH 7.4 containing 1\% TSB [24]. The 
bacterial suspension was adjusted to a concentration of $1 \times 10^{7} \mathrm{CFU} / \mathrm{ml}$. Twenty microlitres of bacterial suspension was mixed with an equal volume of $200 \mu \mathrm{g} / \mathrm{ml}$ HNP-1 or HBD-2 to obtain a final concentration of $100 \mu \mathrm{g} / \mathrm{ml}$ antimicrobial peptide and incubated at $37^{\circ} \mathrm{C}$ in air for $3 \mathrm{~h}$. The viable bacterial count was determined by dropping a 10 -fold serial dilution on Ashdown agar.

\section{Susceptibility to antimicrobial activity of human cathelicidin}

B. pseudomallei susceptibility to cathelicidin LL-37 was tested using a microdilution method [25]. LL-37 was kindly provided by Dr. Suwimol Taweechaisupapong, Department of Oral Diagnosis, Faculty of Dentistry, Khon Kaen University and Dr. Jan G.M. Bolscher, Department of Oral Biochemistry, Van der Boechorststraat, Amsterdam, The Netherlands. A loop of bacteria was washed 3 times in $1 \mathrm{mM}$ potassium phosphate buffer (PPB) pH 7.4 and suspended in the same buffer. The bacterial suspension was adjusted to a concentration of $1 \times 10^{7} \mathrm{CFU} / \mathrm{ml}$. Fifty microlitres of suspension was added into wells containing $50 \mu \mathrm{l}$ of a 2 -fold serial dilution of human cathelicidin in PPB (to obtain a final concentration of 3.125-100 $\mu \mathrm{M}$ ), The mixture was incubated at $37^{\circ} \mathrm{C}$ in air for $6 \mathrm{~h}$ and viability of bacteria was determined by plating a 10 -fold serial dilution on Ashdown agar. The assay was performed in duplicate.

\section{Growth in low oxygen and anaerobic conditions}

An overnight culture of B. pseudomallei on Ashdown agar was suspended in PBS and adjusted to a concentration of $1 \times 10^{8} \mathrm{CFU} / \mathrm{ml}$. The bacterial suspension was 10 -fold serially diluted and $100 \mu \mathrm{l}$ spread plated on Ashdown agar to obtain approximately 100 colonies per plate. Three sets of plates were prepared per isolate and incubated separately at $37^{\circ} \mathrm{C}$ in 3 conditions: (i) in air for 4 days (control); (ii) in an GasPak EZ Campy Pouch System to produce an atmosphere containing approximately $5-15 \%$ oxygen (BD) for 2 weeks; or (iii) in an anaerobic jar (Oxoid) with an $\mathrm{O}_{2}$ absorber (AnaeroPack; MGC) for 2 weeks and then re-exposed to air at $37^{\circ} \mathrm{C}$ for 4 days. The mean colony count was determined for each morphotype from $5 \mathrm{~B}$. pseudomallei isolates after incubating bacteria in air for 4 days (control). \% colony count for each isolate incubated in 5-15\% oxygen or in an anaerobic jar for 14 days was calculated in relation to the colony count of the control incubating bacteria in air for 4 days.

\section{Colony morphology switching}

Seven conditions were observed for an effect on morphotype switching, as follows: (i) culture in TSB in air with shaking for $28 \mathrm{~h}$, (ii) intracellular growth in macrophage cell line for $8 \mathrm{~h}$, (iii) exposure to $62.5 \mu \mathrm{M} \mathrm{H}_{2} \mathrm{O}_{2}$ in LB broth for $24 \mathrm{~h}$, (iv) growth in LB broth at $\mathrm{pH} 4.5$ for $24 \mathrm{~h}$, (v) exposure to $2 \mathrm{mM} \mathrm{NaNO}_{2}$ for $6 \mathrm{~h}$, (vi) $6.25 \mu \mathrm{M}$ LL-37 for $6 \mathrm{~h}$, and (vii) incubation in anaerobic condition for 2 weeks and then re-exposure to air for 4 days. All experiments were performed using the experimental details described above. B. pseudomallei morphotype on Ashdown agar following incubation in air at $37^{\circ} \mathrm{C}$ for 4 days was defined and compared with the starting morphotype. Morphotype switching was presented as the proportion (\%) of alternative types in relation to the total colonies present. Assays of resistance to HNP-1, HBD-2, lysozyme and lactoferrin employed a drop method to assess bacterial survival and colony morphology could not be accurately determined.

\section{Statistical analysis}

Statistical analysis was performed using the statistical program STATA version 10.1. Log transformation of continuous dependent variables was performed as appropriate. Nested repeated measures ANOVA was used to test continuous dependent variables between 3 isogenic morphotypes. A difference between 3 morphotypes was considered to be statistically significant when the $P$ value was less than or equal to 0.05 , after which pairwise comparisons were performed between each morphotype. All $P$ values for pairwise analyses were corrected using the Benjamini-Hochberg method for multiple comparisons [26].

\section{Acknowledgements}

We are grateful to Dr. Suwimol Taweechaisupapong and Dr. Jan G.M. Bolscher for providing LL-37, to Dr. Sue Lee for statistical advice and to Mrs. Vanaporn Wuthiekanun for providing B. pseudomallei isolates. We thank staff at the Mahidol-Oxford Tropical Medicine Research Unit for their assistance and support. S.T was supported by a Siriraj Graduate Thesis Scholarship, Thailand. N.C. was supported by a Wellcome Trust Career Development award in Public Health and Tropical Medicine, UK, and a Thailand Research Fund award, Thailand.

\section{Author details}

${ }^{1}$ Department of Microbiology and Immunology, Faculty of Tropical Medicine, Mahidol University, Bangkok, Thailand. ${ }^{2}$ Mahidol-Oxford Tropical Medicine Research Unit, Faculty of Tropical Medicine, Mahidol University, Bangkok, Thailand. ${ }^{3}$ Department of Immunology, Faculty of Medicine Siriraj Hospital, Mahidol University, Bangkok, Thailand. 'Department of Tropical Hygiene, Faculty of Tropical Medicine, Mahidol University, Bangkok, Thailand. ${ }^{5}$ Center for Clinical Vaccinology and Tropical Medicine, Nuffield Department of Clinical Medicine, University of Oxford, Churchill Hospital, Oxford, UK. ${ }^{6}$ Department of Medicine, University of Cambridge, Addenbrooke's Hospital, Cambridge, UK.

\section{Authors' contributions}

ST carried out the experiments and data analysis. AT isolated and maintained isogenic morphotypes. DL participated in statistical analysis. SK and ND provided materials and intellectual comments. SJP participated in the design of the study, and assisted in the writing of the manuscript. NC participated in the design of the study, data analysis and coordination and writing of the manuscript. All authors read and approved the final manuscript.

Received: 23 June 2010 Accepted: 30 November 2010 Published: 30 November 2010 
References

1. Cheng AC, Currie BJ: Melioidosis: epidemiology, pathophysiology, and management. Clin Microbiol Rev 2005, 18:383-416.

2. Wiersinga WJ, van der Poll T, White NJ, Day NP, Peacock SJ: Melioidosis: insights into the pathogenicity of Burkholderia pseudomallei. Nat Rev Microbiol 2006, 4:272-282

3. Chaowagul W, Suputtamongkol Y, Dance DA, Rajchanuvong A, Pattaraarechachai J, White NJ: Relapse in melioidosis: incidence and risk factors. J Infect Dis 1993, 168:1181-1185.

4. Currie BJ, Fisher DA, Anstey NM, Jacups SP: Melioidosis: acute and chronic disease, relapse and re-activation. Trans R Soc Trop Med Hyg 2000, 94:301-304.

5. Adler NR, Govan B, Cullinane M, Harper M, Adler B, Boyce JD: The molecular and cellular basis of pathogenesis in melioidosis: how does Burkholderia pseudomallei cause disease? FEMS Microbiol Rev 2009, 33:1079-1099.

6. DeShazer D, Brett PJ, Woods DE: The type II O-antigenic polysaccharide moiety of Burkholderia pseudomallei lipopolysaccharide is required for serum resistance and virulence. Mol Microbiol 1998, 30:1081-1100.

7. Egan AM, Gordon DL: Burkholderia pseudomallei activates complement and is ingested but not killed by polymorphonuclear leukocytes. Infect Immun 1996, 64:4952-4959.

8. Wikraiphat C, Charoensap J, Utaisincharoen P, Wongratanacheewin S, Taweechaisupapong S, Woods DE, Bolscher JG, Sirisinha S: Comparative in vivo and in vitro analyses of putative virulence factors of Burkholderia pseudomallei using lipopolysaccharide, capsule and flagellin mutants. FEMS Immunol Med Microbiol 2009, 56:253-259.

9. Charoensap J, Utaisincharoen P, Engering A, Sirisinha S: Differential intracellular fate of Burkholderia pseudomallei 844 and Burkholderia thailandensis UE5 in human monocyte-derived dendritic cells and macrophages. BMC Immunol 2009, 10:20.

10. Puthucheary SD, Nathan SA: Comparison by electron microscopy of intracellular events and survival of Burkholderia pseudomallei in monocytes from normal subjects and patients with melioidosis. Singapore Med J 2006, 47:697-703

11. Chantratita N, Wuthiekanun V, Boonbumrung K, Tiyawisutsri $R$, Vesaratchavest M, Limmathurotsakul D, Chierakul W, Wongratanacheewin S, Pukritiyakamee S, White NJ, et al: Biological relevance of colony morphology and phenotypic switching by Burkholderia pseudomallei. J Bacteriol 2007, 189:807-817.

12. Agerberth B, Charo J, Werr J, Olsson B, Idali F, Lindbom L, Kiessling R, Jornvall H, Wigzell H, Gudmundsson GH: The human antimicrobial and chemotactic peptides LL-37 and alpha-defensins are expressed by specific lymphocyte and monocyte populations. Blood 2000, 96:3086-3093.

13. Duits LA, Ravensbergen $B$, Rademaker M, Hiemstra PS, Nibbering PH: Expression of beta-defensin 1 and 2 mRNA by human monocytes, macrophages and dendritic cells. Immunology 2002, 106:517-525.

14. Rustad TR, Harrell MI, Liao R, Sherman DR: The enduring hypoxic response of Mycobacterium tuberculosis. PLoS One 2008, 3:e1502.

15. Radtke $A L, O$ 'Riordan $M X$ : Intracellular innate resistance to bacterial pathogens. Cell Microbiol 2006, 8:1720-1729.

16. Breitbach K, Klocke S, Tschernig T, van Rooijen N, Baumann U, Steinmetz I: Role of inducible nitric oxide synthase and NADPH oxidase in early control of Burkholderia pseudomallei infection in mice. Infect Immun 2006, 74:6300-6309.

17. Ekchariyawat P, Pudla S, Limposuwan K, Arjcharoen S, Sirisinha S, Utaisincharoen P: Burkholderia pseudomallei-induced expression of suppressor of cytokine signaling 3 and cytokine-inducible src homology 2-containing protein in mouse macrophages: a possible mechanism for suppression of the response to gamma interferon stimulation. Infect Immun 2005, 73:7332-7339.

18. Loprasert S, Sallabhan R, Whangsuk W, Mongkolsuk S: Compensatory increase in ahpC gene expression and its role in protecting Burkholderia pseudomallei against reactive nitrogen intermediates. Arch Microbiol 2003, 180:498-502.

19. Chantratita N, Wuthiekanun V, Limmathurotsakul D, Vesaratchavest M, Thanwisai A, Amornchai P, Tumapa S, Feil EJ, Day NP, Peacock SJ: Genetic diversity and microevolution of Burkholderia pseudomallei in the environment. PloS Negl Trop Dis 2008, 2:e182.
20. Harada T, Miyake M, Imai Y: Evasion of Legionella pneumophila from the bactericidal system by reactive oxygen species (ROS) in macrophages. Microbiol Immunol 2007, 51:1161-1170.

21. Minta JO, Pambrun L: In vitro induction of cytologic and functional differentiation of the immature human monocytelike cell line U-937 with phorbol myristate acetate. Am J Pathol 1985, 119:111-126.

22. Loprasert S, Sallabhan R, Whangsuk W, Mongkolsuk S: The Burkholderia pseudomallei oxyR gene: expression analysis and mutant characterization. Gene 2002, 296:161-169.

23. Callewaert $L$, Aertsen $A$, Deckers $D$, Vanoirbeek KG, Vanderkelen $L$, Van Herreweghe JM, Masschalck B, Nakimbugwe D, Robben J, Michiels CW: A new family of lysozyme inhibitors contributing to lysozyme tolerance in gram-negative bacteria. PLoS Pathog 2008, 4:e1000019.

24. Jones AL, Beveridge TJ, Woods DE: Intracellular survival of Burkholderia pseudomallei. Infect Immun 1996, 64:782-790.

25. den Hertog AL, van Marle J, van Veen HA, Van't Hof W, Bolscher JG, Veerman EC, Nieuw Amerongen AV: Candidacidal effects of two antimicrobial peptides: histatin 5 causes small membrane defects, but LL-37 causes massive disruption of the cell membrane. Biochem J 2005, 388:689-695.

26. Benjamini $Y$, Hochberg $Y$ : Controlling the false discovery rate: practical and powerful approach to multiple testing. Journal of the Royal Statistical Society Series B (Methodological) 1995, 57:28.

doi:10.1186/1471-2180-10-303

Cite this article as: Tandhavanant et al: Effect of colony morphology variation of Burkholderia pseudomallei on intracellular survival and resistance to antimicrobial environments in human macrophages in vitro. BMC Microbiology 2010 10:303.

\section{Submit your next manuscript to BioMed Central and take full advantage of:}

- Convenient online submission

- Thorough peer review

- No space constraints or color figure charges

- Immediate publication on acceptance

- Inclusion in PubMed, CAS, Scopus and Google Scholar

- Research which is freely available for redistribution

Submit your manuscript at www.biomedcentral.com/submit
C Biomed Central 